\title{
Intergenerational context as an emphasis for design
}

\author{
Dave Harley • Frank Vetere • Geraldine Fitzpatrick • \\ Sri Kurniawan
}

Published online: 24 June 2011

(C) Springer-Verlag 2011

\section{Introduction: universal access and older people}

As populations age across the developed world [18], attention is turning to ways of preserving the quality of life for the growing number of people experiencing an extended old age [22]. Information and communication technologies have great potential for supporting older people to maintain their independence and standard of living [2]. Attempts to make computer-based technologies more accessible to older users have mostly adopted functional approaches, redesigning or adapting user interfaces to reconcile human changes to physical and cognitive abilities [17]. Whilst this approach towards functional accessibility is important and significant in its own right, it struggles to address some of the contextual issues that underlie the meaningful and socially embedded use of such technologies [9]. Contextual issues can undermine the usefulness of functional accessibility when, for example, older people choose not to adopt information and communication

\section{Harley $(\bowtie) \cdot$ G. Fitzpatrick}

Interact Lab, Department of Informatics,

University of Sussex, Falmer, Brighton BN1 9QH, UK

e-mail: D.A.Harley@sussex.ac.uk

G. Fitzpatrick

e-mail: g.a.fitzpatrick@sussex.ac.uk

\section{F. Vetere}

Department of Information Systems, University of Melbourne,

Room 4.57, 111 Barry St., Carlton, VIC, Australia

e-mail: f.vetere@unimelb.edu.au

\section{S. Kurniawan}

Department of Computer Engineering,

University of California Santa Cruz, Engineering 2,

Room 331, Mailstop: SOE 3, Santa Cruz, CA 95064, USA

e-mail: srikur@soe.ucsc.edu technologies at all, seeing them as irrelevant [14] or offering no benefits $[11,16]$ to their social context.

In this special issue, we consider universal access in relation to the inclusion of older people and explore the accessibility of computer-based technologies in its broadest sense, emphasising the social and motivational aspects of use rather than the functional concerns at the interface. The papers explore notions of accessibility, not only from the perspective of redesigning existing technologies to improve access but also investigating the purposeful creation of technology to best meet broader needs and aspirations. In addition to extending ideas of accessibility, the papers also broaden the way older people are typically considered in age-related research. Rather than being characterised as frail and impaired, older people in these papers are active and engaged, seeking opportunities for interactions with the wider community. Specifically, the papers focus on the importance of the intergenerational context as an emphasis for the design of innovative technologies.

\section{The intergenerational context as an emphasis for design}

When considering older people's engagement with new information and communication technologies, it is inevitable that intergenerational contact will play some part in framing these interactions. This is particularly true for familial interactions between grandchildren and grandparents. Grandchildren are often a significant source of expertise for their grandparents when it comes to learning about computer-based technologies [15]. Intergenerational contact also provides an important motivator for older people to engage with new technologies in the first place. 
For example, older people willingly adopt new technologies to fit into the schedules of their adult children (Lindley, this issue) and are eager to engage in SMS and MMS when it strengthens ties with grandchildren [20]. Despite the dramatic changes to everyday family life in developed societies, intergenerational bonds remain very important within families continuing to operate over great distances [5] and provide an incentive for using new computer-based communication technologies.

In addition to the changes in familial interactions, intergenerational contact beyond the bonds of family has also been compromised over the last century with a trend towards a more peer-centred society in which different generations are segregated from one another according to their chronological age. Contact between generations, outside of the family, has in effect become institutionalised, occurring only within a family context or when sanctioned within a professional environment, e.g., between a student and a teacher or a young carer and older person. Non-familial informal interactions between the oldest and youngest generations within a community are now rare $[19,21]$. Thus, opportunities to share experience and resources across generations in a face-to-face manner appear to be diminishing. New computer-based technologies provide opportunities for re-engaging generations in a way that is not constrained by the generational divisions that exist in local communities or by the distances that often exist between family members [4, 7].

The intergenerational context is therefore important for designers and researchers to accommodate as an explicit focus for design efforts. So far these efforts have focused on supporting social connectivity between generations within families through the sharing of presence information via message boards and video links in dispersed family homes $[8,10,13,20]$. Others have focused on the development of computer-based games and activities that augment face-to-face intergenerational play and interactions within families $[3,20]$. These approaches are interesting because they move away from more traditional computerbased communication, such as chat tools and email, and start to explore different modalities as the focus of interaction. The papers in this special issue also explore modalities beyond text-based interactions.

Other efforts to design for an intergenerational context have been driven by much more functional agendas, where adult children need to care for distant older relatives who may be experiencing some cognitive or physical health decline. Examples here include the Digital Family Portraits system [12] and the CareNet Display [1]. These systems basically support passive one-way intergenerational contact by using sensor-based technologies to monitor activities of daily living of the older person and represent these on the display of the remote family member. Whilst such systems are important for supporting remote care arrangements and providing reassurance especially to the adult carer, they also miss the opportunities to support reciprocal interactions and socially based communication. The papers in this issue point to possible ways that both monitoring/reassurance needs can be met as a by-product of more playful or socially meaningful interaction.

\section{This special issue}

Understanding the dynamics of the intergenerational context, both within families and between generations across the broader community, is an important way in which older users can be empowered to participate more fully in the technological innovations of developed society. This special issue explores the design and use of technology for intergenerational connections within families and beyond. It contains a selection of papers solicited at a CHI workshop [6] held in April 2009 and reflects current thinking and research aimed at designing computer-based technologies for both younger and older partners.

Carroll et al. start by reconsidering notions of ageing, framing them not in terms of disabilities in need of repair, but as resources offering benefits to younger generations. This paper contrasts deficit-driven design, which aims to address physical, cognitive and social difficulties associated with ageing, with positive design that looks for opportunities to enhance existing skills and abilities associated with advanced age. The paper reports on the role of technically able older people operating within communitybased multigenerational web projects as organizational firekeepers. The authors identify the positive aspects of older people's involvement in these projects, where they bring a considered and patient approach to organisational planning that complements the experimental and exploratory approach of younger project members.

Davis et al. take an ethnographic approach to investigating face-to-face intergenerational play within families using community-based playgroups. The study explores the roles of grandparents and grandchildren whilst engaging in playful activities, identifying several grandparent roles (e.g., instructor, carer and surrogate toy) and grandchildren roles (e.g., imitator, resistor and rule-master). The paper also provides insights into the nature and characteristics of intergenerational play (e.g., intergenerational interactions are episodic; rules and play-structure are flexible; culture and safety permeate most encounters). These roles and insights are useful in understanding intergenerational play and in informing design decisions for intergenerational technologies.

Lindley describes the in situ deployment of a prototype system called Wayve that enables families to send both 
pictures and hand-written notes to small displays situated in one another's homes. The paper focuses on the experiences of use over almost 3 months by three households of one family, incorporating three generations. The findings point to the value of having displays that are asynchronous and 'glanceable'. It also illustrates how traditional communication patterns are re-interpreted in this lighter-weight communication medium. One example is that grandparents still take more of an effort to 'craft' communications to engage younger family members (which is not reciprocated). Playful games were again an important part of these interactions. Also, time and effort, considered a signifier of 'quality' communication for older people in more traditional media, can still be expressed through creative touches. Traditional patterns of uptake of technology by older people also played out in that the grandmother was reluctant to use the system, but interestingly she was still able to gain value from the system through the use by others and being able to see the messages.

Voida et al. use a mixed-methods approach to examine the intergenerational dynamics of collocated game play within families using the Nintendo Wii games console. They show that the opportunity for intergenerational play is a strong motivator for older players to engage with the Wii initially. Looking at four different generations of gamers, they also identify a number of different generational roles that are assumed during game play. The authors group these into five intergenerational pairings (decision maker/ negotiator; configurer/bystander; instructor/instructed; discouraged gamer/encourager and strategizer, and performer/ audience) that frame game play and the intergenerational dynamics within it. The roles are often reversed here with younger players often being the holders of technical knowledge with regards to the Wii and teaching it to their older relatives (with mixed results). The authors also highlight the importance of intermediary generations as enablers of more diverse intergenerational play (i.e., between the youngest and oldest) and as further sources of informal learning of technical literacy. They conclude by offering design suggestions that will encourage intergenerational participation as part of Wii game play.

Derboven et al. present a design-oriented study that looks at opportunities for supporting distributed collaborative gaming between different generations of a family using a 'brain training' game based on grocery shopping activities. The game under review forms part of a preexisting care-based system called the TransCare project, which has been designed to support Flemish older people suffering from chronic or degenerative illness in Belgium. The study focuses on the implications of video chat facilities within the game as part of intergenerational game play and communication between grandparents and grandchildren. The authors again highlight the role of younger players as teachers to older players, suggesting that explicit opportunities for such role reversals should be introduced into game design. In addition, the authors suggest incorporating extensive practice modes with shared synchronised learning conditions, which would be more conducive to this kind of intergenerational instruction and learning.

Finally, Gonzalez et al. explore the use of online photo sharing via the website Flickr for family narratives and 'baby storytelling', by which the everyday activities of young grandchildren in the UK are communicated back to geographically distant grandparents in Malaysia. Through interviews with the families and using a content analysis of the photo-based narratives, the authors show how a sense of family connection is maintained through the careful crafting of visual and textual media by parents. These narratives convey the ongoing everyday development of grandchildren to their grandparents, providing them with a continuing sense of emotional involvement and a strong motivation for learning how to use computers and the Internet. In this study, the intermediary generation (i.e., parents and their siblings) is shown to be pivotal in creating the family narratives and in supporting grandparents to learn about and use computers.

\section{Reflecting across the papers}

Collectively, these papers point to the importance of the intergenerational context in providing an understanding of the meaningful activity between older and younger people, and motivating older users in particular to learn and use computer-based technologies when they might not otherwise see them as relevant or beneficial. In addition, these papers highlight the importance of the social roles assumed by intergenerational partners as part of their interactions, defining the opportunities for reciprocity that become an integral part of ensuing exchanges. Such roles are an intrinsic part of intergenerational contact even before technology is added to the mix (Davis et al.) with older partners controlling the parameters of interaction to define a safe space for play. When intergenerational contact is mediated by computer-based technologies these roles are often reversed with control of certain interactional dynamics transferring to the younger partner or intermediary generations (Voida et al.; Derboven et al.). Managing this role reversal appears to be an important part of these interactions requiring openness to learning through younger instruction from older partners, and a mature attitude towards teaching from the younger ones. The research embodied by these papers leads to ask questions about ways that information and communication technologies within intergenerational contexts might provide overt and transparent control over this role management, perhaps 
with playful uses incorporating role management into the play itself.

Reciprocity is an important aspect of the intergenerational contact, underlying the establishment of meaningful computer-mediated roles. Across all the papers, asymmetry of effort was shown to be an issue for intergenerational contact with older people (Lindley; Davis et al.; Carroll et al.) often showing greater consideration and commitment to the dynamics of play and communication than their younger partners. Developing a shared commitment to computer-mediated interactions is therefore a challenge for design. Again opportunities for role reversal and role play may help in this regard.

The papers also find that photographs can be significant in intergenerational interactions. Photographs are carriers of 'lightweight messages' between older adults and their extended families (Lindley), and a way for grandparents to be part of the mundane, yet important, changes to their grandchildren living abroad (Gonzales et al.). Photographs act as convenient carriers of everyday life, facilitating easy expression, and mediating possible barriers between generations. In many ways, which are both complex and nuanced, photographs embody the values and provide insight into the social and motivational aspects of intergenerational interactions.

At their root, the papers in this special issue explore technological opportunities for establishing the mutual involvement of alternate generations and offer specific design suggestions that can support and promote such intergenerational connections. The papers focusing on intergenerational contact within families highlight the importance of games, play and playfulness (Voida et al.; Derboven et al., Davis et al.) as means of connecting diverse generations. This is apparent even in cases where the technology is ostensibly for communication rather than game playing per se (Lindley; Gonzalez et al.). The important point here seems to be that shared playful activity is of a form that both generations can easily engage with and engenders the openness to interaction required for acquiring new technical literacies. The use of interactional modes that move beyond traditional desktop interactions were particularly successful at harnessing intergenerational capabilities (Carroll et al.) employing visual (Lindley; Gonzalez et al.) and embodied modes (Davis et al.) rather than just keyboard text input. The reasons for this remain largely implicit in these papers as aspects of design. Further research could seek to clarify why such modes are appropriate to intergenerational contact in particular.

\section{Conclusions}

This special issue highlights the importance of the intergenerational context as an emphasis for the design of information and communication technologies. Apart from the unique and valuable contributions of each paper individually, together the papers extend the intergenerational research agenda in at least two important ways. First, the papers extend notions of accessibility beyond the interface to include the social and motivational aspects of access. Second, the papers extend notions of designing for older people beyond the need to address problems associated with age-related physical and cognitive impairments, opportunities for reconnection and engagement with the extended family and broader community. Collectively, they provide a fascinating insight into current research trends and issues.

\section{References}

1. Consolvo, S. Roessler, P., Shelton, B.: The CareNet display: lessons learned from an in home evaluation of an ambient display. In: Proceedings Ubicomp2004, Springer, Sept 2004

2. Czaja, S.J., Charness, N., Fisk, A.D., Hertzog, C., Nair, S.N., Rogers, W.A., et al.: Factors predicting the use of technology: findings from the Center for Research and Education on Aging and Technology Enhancement (CREATE). Psychol. Aging 21, 333-352 (2006)

3. Davis, H., Skov, M.B., Stougaard, M., Vetere, F.: Virtual box: supporting mediated family intimacy through virtual and physical play. In: Proceedings of the 19th Australasian Conference on Computer-Human interaction: entertaining user interfaces (Adelaide, Australia, November 28-30, 2007). OZCHI '07, vol. 251, pp. 151-159. ACM, New York (2007)

4. Gonzalez, V.M., Kurniawan, S.H.: On new media for intergenerational communication: the case of Geriatric 1927. In: Proceedings of 2008 IEEE International Symposium on Technology and Society (ISTAS 08), pp. 1-4. IEEE (2008)

5. Grundy, E., Murphy, M., Shelton, N.: Looking beyond the household: intergenerational perspectives on living kin and contacts with kin in Great Britain. Popul. Trends 97, 33-41 (1999)

6. Harley, D.A., Kurniawan, S.H., Fitzpatrick, G., Vetere, F.: Age matters: bridging the generation gap through technology-mediated interaction. In: Proceedings of the 27 th international conference extended abstracts on Human Factors in Computing Systems, Boston, MA, USA, 04-09 April 2009. CHI '09: 4799-4802 ACM, New York, NY

7. Harley, D., Fitzpatrick, G.: YouTube and intergenerational communication: the case of Geriatric1927. Univ. Access Inf. Soc. 8(1), 5-20 (2009)

8. Hutchinson, H., Mackay W., Westerlund B., Bederson B., Druin A., Plaisant C., Beaudoin-Lafon M., Conversy S., Evans H., Hansen H., Roussel N., Eiderback B., Lundquist S., Sundblad Y.: Technology probes: inspiring design for and with families. In: Proceedings of the CHI2003, ACM Press, pp. 17-24 (2003)

9. Kelly B., Sloan D., Brown S., Seale J., Petrie H., Lauke P., Ball S. (2007) Accessibility 2.0: people, policies and processes. In: Proceedings of the 2007 International Cross-Disciplinary Workshop on Web Accessibility (W4A), Banff, Canada, 7-8 May 2007. ACM Press, New York, pp. 138-147. http://www.ukoln. ac.uk/web-focus/papers/w4a-2007/. Accessed 1 June 2009

10. Lindley, S.E., Harper, R., Sellen, A.: Designing a technological playground: a field study of the emergence of play in household messaging. In: Proceedings of the 28th international conference 
on human factors in computing systems, Atlanta, Georgia, USA, 10-15 April 2010. CHI '10. ACM, New York, NY, pp. 23512360 (2010)

11. Melenhorst, A., Rogers, W., Bouwhuis, D.: Older adults' motivated choice for technological innovation: evidence for benefitdriven selectivity. Psychol. Aging 12(1), 190-195 (2006)

12. Mynatt, E., Rowan, J., Craighill, S., Jacobs, A.: Digital family portraits: providing peace of mind for extended family members. In: Proceedings of the ACM conference on human factors in computing systems (CHI2001), ACM Press, pp. 333-340 (2001)

13. Plaisant, C., Clamage, A., Browne Hutchinson, H., Bederson, B.B., Druin, A.: Shared family calendars: promoting symmetry and accessibility. ACM ToCHI 13, 313-346 (2006)

14. Selwyn, N., Gorard, S., Furlong, J., Madden, L.: The information aged: older adults' use of information and communications technology in everyday life. Ageing Soc. 23, 561-582 (2003)

15. Selwyn, N.: The social processes of learning to use computers. Soc. Sci. Comput. Rev. 23(1), 122-135 (2005)

16. Sharit, J., Czaja, S.J., Perdomo, D., Lee, C.C.: A cost-benefit analysis methodology for assessing product adoption by older user populations. Appl. Ergonomics 35, 81-92 (2004)
17. Stephanidis, C. (ed.): User Interfaces for All: Concepts, Methods and Tools. Lawrence Erlbaum Associates, New York (2001)

18. United Nations: World Economic and Social Survey 2007: Development in an Ageing World. United Nations, New York. http://www.un.org/esa/policy/wess/wess2007files/wess2007.pdf. Accessed 10 October 2007

19. Vanderbeck, R.M.: Intergenerational geographies: age relations, segregation and Re-engagements. Geogr. Compass 1(2), 200-221 (2007)

20. Vetere, F., Davis, H., Gibbs, M., Howard, S.: The magic box and collage: responding to the challenge of distributed intergenerational play. Int. J. Human Comput. Stud. 67, 165-178 (2009)

21. Williams, A., Nussbaum, J.F.: Intergenerational Communication Across the Lifespan. Lawrence Erlbaum Associates, Mahwah, NJ (2001)

22. World Health Organisation (2002) Active ageing: a policy framework. http://whqlibdoc.who.int/hq/2002/WHO_NMH_NPH_ 02.8.pdf. Accessed 17 February 2009 